\title{
CORRESPONDENCE
}

\section{Young people and consent to treatment}

Crome \& Myton's (2004) article on pharmacotherapy in dual diagnosis was excellent, especially for its inclusion of issues relating to young people with substance misuse problems.

However, there was an error, in that the authors state that 'for young people under the age of 16, explicit consent [to treatment] from a parent or guardian is required' (p. 415). This is not the case.

In his review of guidance from the Department of Health, Harbour cites the recommendation that young people under the age of 16 who have

'the capacity and understanding to take decisions about their treatment are also entitled to make decisions about the use and disclosure of information they have provided in confidence (e.g. they may be receiving treatment or counselling about which they do not want their parents to know)' (Department of Health, 2003; cited in Harbour, 2004).

Crome, I. B, \& Myton, T. (2004) Pharmacotherapy in dual diagnosis. Advances in Psychiatric Treatment, 10, 413-424. Department of Health (2003) Confidentiality: NHS Code of Practice. London: Stationery Office.
Harbour, H. (2004) Understanding children and young people's rights to confidentiality. Child and Adolescent Mental Health, 9, 187-190.

Julie Withecomb Consultant Adolescent Forensic Psychiatrist, Bracton Centre, Bracton Lane, Leyton Cross Road, Dartford, Kent DA2 7AP, UK.

\section{Author's response}

Of course, Dr Withecomb is correct. We should have stated that, although we prefer young people to participate in treatment (especially prescribing) with parental consent, if they are assessed as having the capacity and understanding to make decisions about treatment, they can decide about disclosure of information.

Ilana B. Crome Academic Director of Psychiatry, Professor of Addiction Psychiatry, Academic Psychiatry Unit, Keele University Medical School (Harplands Campus), Hilton Road, Harpfields, Stoke on Trent ST4 6TH, UK. E-mail: pca03@keele.ac.uk.

\section{CORRIGENDUM}

Bradley, E. \& Lofchy, J. (2005) Learning disability in the accident and emergency department. APT, 11, 45-57.

The second column of text on p. 48 should begin:

Inquiry about vision and hearing should be made, as deterioration in sensory functioning can give rise to changes in behaviour.

Problems in expectations and supports

Individuals with learning disabilities are much more dependent on external structures. Emotional problems often arise when expectations and supports change (e.g. a recent move; a change in staff - staff turnover can be very high in some group homes; a change in daily life schedule, such as start of school or work; a change in work activities) or are inappropriate (e.g. unrealistic expectations of completing tasks or travelling independently).

The final section of the second column of text on p. 54 should begin:

Hospital admission

Sovner \& Hurley (1991) list a number of questions that should be asked if in-patient admission is considered: 